\title{
Teaching Undergraduate Researchers to Theorize and Practice Narrative Inquiry
}

\section{Jaqueline McLeod Rogers}

\begin{abstract}
Narrative inquiry has become a growing part of scholarly work across disciplines and a common part of student writing. I begin this article by proposing that undergraduate students can benefit from a course that teaches them about narrative, a mode of knowing many theorists claim is unique to humans and basic to our understanding. Students who understand the intersections of epistemology and narrative are more likely to avoid the intellectual pratfalls of writing narratives that are static, simple or entirely self-focused. The remainder of the article proposes texts and themes to constitute a course focused on narrative thinking and writing. I suggest that the major topics to take up are the role of narrative in human history, in contemporary scholarship, and in feminist and postmodern theory. Issues of interest include the function of narrative as evidence, the role of the personal and of experience in knowledge building according to feminist and postmodern theorizing, the ethical responsibility of narrative writers and the interactive engagement of readers. Students who make connections amongst examples, theory and personal experience not only gain a better understanding of narrative scholarship but are also more likely to enact its authentic practice.
\end{abstract}

\section{Key words narrative inquiry, narrative argument, feminist narrative, epistemology, ethics}

\section{Résumé}

L'enquête narrative constitue une méthode de plus en plus importante dans la recherche académique menée dans plusieurs disciplines ainsi que dans les travaux étudiants. Je commence donc cet article en suggérant que les étudiants du premier cycle peuvent tirer avantage d'un cours portant sur la narration, une pratique qui, selon de nombreux théoriciens, est propre à l'être humain et fondamental pour sa compréhension du monde. À cet égard, les étudiants qui reconnaissent les manières dont l'épistémologie et la narration s'enchevêtrent sont moins propices à écrire des narrations trop statiques, simplistes ou nombrilistes. La suite de mon article propose des textes et des thèmes qui seraient pertinents pour un cours sur la pensée et l'écriture narratives. À mon avis, le sujet le plus important dans un tel cours serait le rôle de la narration dans l'histoire humaine, dans les recherches contemporaines et dans les théories féministes et postmodernes. Parmi les questions les plus intéressantes, il y aurait la fonction de la narration en tant que preuve, le rôle des expériences personnelles dans la construction du savoir selon les approches féministe et postmoderne, la responsabilité morale d'auteurs de narrations, et l'engagement du lecteur avec la narration. Les étudiants capables d'établir des liens entre théories, exemples et expériences personnelles acquerraient non seulement une meilleure compréhension de l'enquête narrative mais seraient aussi plus enclins à appliquer ses pratiques véritables. 


\section{Mots clés enquête narrative, argument narratif, narration féministe, épistémologie, éthique}

Narrative inquiry has become a growing part of scholarly work across disciplines over the past decades and a common part of the student writing repertoire. Students are asked to write reflectively or autobiographically in a variety of courses, not only to engage with course work and textual ideas but also for high-stakes practical purposes such as securing admission to a program or permission to pursue research. Many enjoy this work, although some express uncertainty about its rigor or purpose. First-year students, many trained by overcorrecting high school teachers to banish the "l" pronoun to accomplish objectivity, are often puzzled by being invited to "enter" their texts, and ask "Why am I writing about myself in university? I thought we were supposed to learn about important subjects and leave ourselves behind." More advanced students have usually encountered the request in other courses and have reported finding narrative work "surprisingly" useful. For example, when I gave the first in a series of narrative writing assignments in a course called "Narrative Thinking and Writing," one student spoke up to encourage the others by reporting that a similarly reflective assignment in a literature course, while self-indulgent on the surface, eventually led her to think "about what I knew about the topic, and it really helped me focus."

Students are often ambivalent narrative practitioners because they are assigned the task without any theoretical underpinning to explain the history and value of narrative work. In writing classes, for example, many teachers assign only one personal narrative essay as a non-theorized opening exercise, before turning to more conventional scholarly genres like critique and research argument. On the other hand, some writing teachers refuse to teach narratives altogether, objecting that narrative writing encourages students simply to dredge up an unexamined chunk of experience as the basis for a knowledge claim or insight. As Cynthia Lewiecki-Wilson (1999) points out, storytelling can be no more than an opportunity to rehash unexamined assumptions, so that students "do not reflect on or budge in their beliefs"(p. 108).

Yet simple transcription of past experiences bears as little relation to the practice of narrative inquiry as read-and-retrieve exercises do to the process of critical reading. To understand life through a narrative lens involves dynamism in at least these ways: the shape and details of the experiences change in memory and then change again in the process of writing, for words come with echoes and restrictions; writers themselves change, so that they are no longer the same as when the event occurred; and how writers understand experience is constantly developing, so that the meaning of experience is unending palimpsest. The term "narrative inquiry" picks up on this dynamism by implying that the act of theorizing is a go-forward process. To engage in authentic narrative inquiry requires writers to deliberate and reflect on experience, and often to revise or "restory" it in a way that is responsive to new experiences and the stories of others.

Canadian education researchers D. Jean Clandinin and F. Michael Connelly (1990) emphasize revision and collective authoring as key elements of narrative inquiry, which they define as "a process of collaboration involving mutual storytelling and 
restorying as the research proceeds" (p.4). Inter-subjectivity-thinking with and through others-introduces the concept that knowledge is not idiosyncratic or parochial nor fixed, but interactive and negotiated, so that our subjective knowing of objects or phenomena can be corrected or deepened through consultation. Story as a written result of inquiry is not produced or offered to readers as a polished nugget of past experience or as a transcription of found, forever truth, but as a personal representation of subject-object interaction.

To bring narrative into the classroom in a way that ensures students recognize it as a call to interrogate personal experience in light of competing discourses-so that it is framed as active and interactive inquiry rather than a mere retelling of what has been-writing teachers need to accompany the practice of narrative writing with readings that examine the roots of storytelling in human thinking and that also extend these roots into contemporary rhetorics. Students need to understand that the turn to narrative expression is linked to the ways subjectivity and objectivity have been recharacterized in postmodern thought. If in place of a stable self we have a variety of subject positions that play out in response to social custom, then narration provides a flexible framework for constructing and revising identity and world view. Across a variety of disciplines, researchers who take a "storied" view of life believe that each of us interprets new experience by turning it into a story that fits the framework of stories we have already developed. Andrea Lunsford (1999) describes the interdisciplinary reach of the narrative turn- "from the scientific to the business-oriented to the artistic"-as particularly responsive to postmodern discourse theories that not only refigure the influence of position and perspective on perception, but that also take up the symbolic nature of language and the storied constructions of human understanding: "[T]hese stories, even those that rest on 'true' or 'real' events, must take on the status of artifice, for the very fact of their embeddedness in language means that they must be crafted and that they are metaphoric in nature-representative of something else, something not ever there" (p. 345).

While the subject position of the knower has been widely theorized, the nature of the phenomenon being investigated-the object-has also been reconceived in posttheorizing. Philosopher Michael Polanyi (1958) rejected traditional conceptions of scientific objectivity as a myth to simplify scientific work, painting it as a controlled undertaking with observable content and replicable form. Instead, he declared that inquiry requires a bridge of what he called "Personal Knowledge" to make connections between mind and materiality:

We shall find Personal Knowledge manifested in the appreciation of probability and of order in exact sciences and see it at work even more extensively in the way descriptive sciences rely on skills and connoisseurship. At all these points the act of knowing includes an appraisal; and this personal coefficient, which shapes all factual knowledge, bridges in doing so the disjunction between subjectivity and objectivity. (p. 17)

Recent arguments from spatial theory continue to complicate our understanding of the world of things, teasing out gaps between material reality and the various forms of its representation: while it might be true that a building actually exists, for example, my apprehension of it is a blend of "real and imagined elements," influenced not only by where I stand but also my discursive memory of buildings - those I have seen in life and 
art, in text, and dreams. Using the city as his example of a material place, James Donald (1999) argues that our understanding of the city includes "not just the cities created by the 'wagging tongues' of architects, planners, and builders, sociologists and novelists, poets and politicians, but also the translations of the places they have made into the imaginary reality of our mental life" (p. 8). By this argument, language is not only symbolic of things, but the words we use to call up things are already freighted with associative meanings from past uses-layered and archival. Borrowing the thirdspace concept of Henri LeFebvre, theorists like Donald and Edward Soja (1996) argue that individuals are truly responsive to life by creatively imagining how material and social realms might interact. Narrated thirdspace insights are subjective, responsive, provisional, mobile.

Studying some of this narrative theory is useful to student writers before, or accompanying, the practice of narrative writing if they are to appreciate that they are doing more than talking about themselves to avoid the "real subject," more than remembering past antics and entertaining anecdotes, more than brandishing personal opinion. Instead, with theory they begin to conceptualize the narrative process as involving an examination of the changing connections between self and subject.

The question I am addressing in the sections that follow is how to constitute a course to teach undergraduate students about narrative. The topics, readings, and assignments outlined in the pages ahead are loosely based on a sequence I have developed for a course called "Narrative Thinking and Writing," an upper-year course in the Department of Rhetoric, Writing and Communications at The University of Winnipeg which examines the theory and practice of narrative scholarship across disciplines. This sequence offers students a way to understand the roots of narrative thinking, the contemporary narrative turn, and the power and limits of this form of inquiry.

\section{Narrative Knowing Then and Now}

Looking at the deep roots of story-telling in human communication is a good place to begin a course studying narrative. The chapter on oral culture from Walter Ong's (2002) Orality and Literacy introduces the concept of narrative as an interactive and dialogical form of discourse. Ong's presentation sets up a contrast between narrative as the predominant discourse of orality and argument as that of print literacy, so that students begin to differentiate between the two modes. Ong describes narrative as a communal form of expression, embodied and oral rather than reliant on technologies and unfolding outside one's material being. Its parts are bound together by coordinators (first $\mathrm{x}$ happens, and then $\mathrm{y}$, and then. . .), so that it grows by aggregation rather than by more complex relational subordination. It tends to talk about things concrete and particular. By contrast, textual argument deals in abstractions and is linked by subordination. It is produced outside the body, in print text, usually as a result of independent rather than collective thinking. By becoming familiar with these areas of contrast Ong establishes between narrative and argument, students gain access to a conceptual tool that provides broad-based rather than delicate or definitive understanding. It is useful to anchor the course in an historical perspective, for this long view helps students to cultivate an understanding of narrative as a basic form of human communication, a mode post-moderns have not devised but revised as a way of responding to life. 
Jerome Bruner (1986) is another theorist who provides an historic perspective, encouraging students to think about narrative as a basic way of knowing or conceptualizing. He makes clear the term refers to something bigger than a writing style. In an opening chapter, "Two Modes of Thinking," from Actual Minds, Possible Worlds, Bruner draws a rather extreme picture of the differences between the two modes of narrative and argument (paradigm). In this chapter, Bruner tells us that paradigmatic argument is a well-established mode of thinking, for which we have developed "powerful prosthetic devices for helping us to carry out its work: logic, mathematics, sciences, and automata for operating in these fields" (p.13). Argument deals in abstraction and generalization and is judged to be true, correct, or adequate. By contrast, we appreciate narratives that are "good," "gripping" or "believable" (Bruner, 1986, p. 13). They deal with particular events and characters, and tell us something about how human intentions play out over time.

By linking narrative to particular situations, temporality, and the study of complicated cause and effect, Bruner (1986) begins to respond to the question "why narrative?"- - to the question of what this mode of thinking can contribute to knowing about human life that more abstract argumentation cannot. His presentation emphasizes how narrative enables writers to consider the details of individual cases, the inescapability of the effects of time, and the complex latticework of human interaction. Narrative engages the full powers of mind, not ruled by reason alone but admitting the play of imagination. By contrast, he casts paradigmatic thinking as relatively precise yet heavy-footed, shaping a "well-defined world" that relies "on the verification of well-formed propositions about how things are" (Bruner, 2002, p. 102).

Looking at this history-particularly the reading from Ong-some students may associate narrative with primitive thinking and see argument as the advanced position that developed alongside literacy, working with a humanist model of human progress. This reading of history provides a point of entry for class discussion of the assumption that history and human progress unfold together; this is also a strategic moment to present the possibility that we may be in the process of moving into a post-literate stage-a stage that shares more features in common with orality than literacy and that relies on electronic media as the predominant mode of communication. Students who are interested in electronic communication might be directed to review how Ong connects our current stage of virtual communication with the conventions of narrative rather than argument, suggesting something of a return to narration. While print-media arguments tend to be abstract, complex and developed by and for a mind working alone, narratives developed by oral and virtual cultures tend to have collective authorship and audience and, grammatically, to be more simple and concrete. Ong's model not only gives narrative a past, but links it to contemporary life, where communication in the virtual community can be understood as renewing and revising forms of narrativity.

At this point, I introduce two short readings from education research to extend the idea that a narrative approach can capture insights about human life that other approaches cannot replicate. "Small is Beautiful"_education researcher Glenda Bissex's (1996) advocacy of case study as a way of learning about learning-directly raises questions about what qualitative work can accomplish. Perhaps her strongest contention is that the primary purpose of narrative particularizing is to promote 
understanding rather than furnish proof: The question one should ask of a narrative is not "what does it prove" but "what did I learn?" She points out that in the study of human questions, we should be interested in particular details and exceptions, and in complicated, multi-level causes and effects, rather than attempting to generalize by constraining our studies to causal relationships that can be measured in a nonnaturalistic laboratory environment.

The opening chapter of Narrative Inquiry, by education researchers D. Jean Clandinin and F. Michael Connelly ((2000), continues to explore reasons for taking a narrative approach, offering a cook's tour of interdiscplinary perspectives on the purposes of narrative research, with helpful summaries of positions staked by Clifford Geertz and Catherine Bateson in particular. They point out that these writers use narrative to interrogate change and continuity, both in the writers and in the worlds they regard and record. For both Bateson and Geertz, temporality is at the core of narrative thinking and writing, more than functioning as a mere structuring device.

To complete this unit of introductory theorizing, students need an opportunity to write an in-class reflection on key ideas: they can compare how Bruner and Ong characterize the differences between narrative and argument, or compare what Bateson and Geertz say about temporality and knowing. Turning from theory to examples, they can read several personal narrative essays, chosen as models because they canvas unique personal experiences to address a common topic: how writers deal with the burden of family history (Maxine Hong Kingston's "No-Name Woman" in Woman Warrior and a selection from Joy Kogawa's Obason) or what writers have learned about language (a chapter from Eva Hoffman's Lost in Translation or from Marianne Hirsch's Family Frames) or about the process of learning or education (a chapter from Mike Rose's Lives on the Boundary). In response to reading these examples, students can write the first major assignment, a personal narrative essay, in which they draw on their own experience to develop an insight about a broad field of human experience like family history, language and literacies, or learning. This assignment calls for a nonresearched personal story intended to engage readers by striking chords of resonance; readers should gain insight into a human problem, whether it resonates with them personally or helps them to see another point of view or way of life.

A follow-up exercise to encourage students once again to connect theory and practice asks them to attempt to encapsulate the main insight of their narrative in a sentence and to sketch how their view of the issue has changed over time. Some may find that their central idea resists being crystallized in thesis-sentence form because it was woven throughout the narrative, more tacit, subtle and emergent than fully formed. Some may also characterize themselves as continuing to respond to the issue, rather than having taken a side and committed to a position. This reflective exercise leads students to have a new appreciation of the way Ong and Bruner associate thesis and definitive meaning and outcome with arguing rather than story-making; returning to this theory also allows for fertile class discussion of the narrative inquiry process, with students taking stock of their own experience of learning by doing.

\section{From Personal Narrative to Narrative Argument: From Story-with-a-point to Point- driven Story}


After writing an experience-based narrative that makes a point or develops an insight, students need to attempt a variant form, a narrative argument that knits in references to outside sources with the aim of contributing to scholarly debate. Rather than conceptualizing narrative and argument as separate modes of thinking as they did in the first unit reading Ong and Bruner and culminating in the personal narrative, in this unit they are linking narrative and argument, preparing to make a case and contribute to scholarly debate by drawing from personal experience. Here is one way to frame assignment directions that describes the move from a story based on personal experience to one that entwines personal experience with textual evidence-to a narrative argument that engages in critical or scholarly debate:

In the personal narrative, you used your experience to provide insight about family, learning or language and identity-about big topics that challenge all of us. You made an argument or provided an insight, but did so in a non-scholarly (life-based) context. This assignment asks you to write a scholarly narrative that responds to an issue debated in academic publications. Support your response by making reference to primary and secondary sources as well as to relevant personal stories. The structure of the whole should be in narrative form: probably most of you will choose to recreate the process of the intellectual journey that has brought you to your current perspective, using an "I" point of view.

To encourage meta-analysis, instructors can ask students to choose a topic related to some aspect of narrative writing and inquiry that has been the focus of composition scholarship and debate, using theory examined in class as well as other sources. The following topic option asks students to consult narrative examples and theory to evaluate the capacity of narrative to deal with the details of particular cases:

Robert Coles, a psychologist, and Mike Rose, an educator, are concerned with responding to human minds (in The Call of Stories and Lives on the Boundary, respectively). Consider why they talk about individuals and tell stories, rather than presenting more conventional forms of evidence. What are some of the advantages and theoretical reasons for taking this qualitative and specific approach to writing about human development? (You can look at other writers in these fields who are working with stories, or look at the growing theory about narrative inquiry. Glenda Bissex's "Small is Beautiful" about the value of case study is also useful here).

Apart from comparing how authors share a common narrative approach, students can also evaluate contrasting approaches, as in the following question about the portrait of aging in realist fiction and in an ethnographic account:

Carol Shields portrays the inner life of an older woman in "Mrs. Turner Cutting the Grass"; in an interpretive ethnography, Barbara Meyerhoff studies the culture of a group of seniors in Number Our Days (which she sets up in narrative terms in the first chapter). Compare the appeal of each (here you can refer to your responses as reader), as well as the capacity of each to expand our understanding. Use theory about the purpose of story and ethnography perhaps what Bruner says about the power of fiction and what John Van Maanen or Norman Denzin say about the uses of ethnographic report.

I have found that students struggle with writing this first narrative argument no matter how many examples we examine. It is not a familiar or fixed-form genre-narrative 
theorist Candace Spigelman (2004) calls it a still-forming "hybrid genre" (p. 14). For story and argument to blend together, most writers locate their narrative in relation to prior scholarships and then offer their narrative position as a perspective rather than the last word, bearing in mind that another convincing narrative argument might invite readers to take a different view.

Apart from looking at a range of examples, I use class time to look at theories that present ways to evaluate the evidentiary value of a narrative so that students become habituated with the role of narrative as a tool for collaborative construction of knowledge rather than seeing it foremost as a vehicle for self-knowledge and expression. Looking at the work of language theorist Walter Fisher (who believes storytelling is the most basic form of human communication) provides students with an expanded definition of narrative as a way to explain most communication situations and, as Julia T. Wood (2004) says in explaining Fisher's rhetorical perspective, introduces standards beyond pure rationality as a way to evaluate a worthwhile idea or way of thinking: "The paradigm shift that Fisher advocated opens up new ways of thinking about communication, persuasion, and belief" so that beyond "evidence and reasoning alone" we also take "[v]alues, emotional arguments, and aesthetic considerations" into account (p. 107). ${ }^{1}$

Fisher established two standards by which to evaluate narrative: coherence and fidelity. Fidelity is in place if a reader appreciates an element of lifelikeness-if the piece resonates with the reader's experiences of what it means to be human, formed on the basis of firsthand experience and cultural expectations. Coherence is achieved when the story parts work together, so that there is internal consistency. Characters seem motivated in the things they do. A well-known example of a story that gets high marks with most students when they apply both criteria is Mike Rose's (1990) Lives on the Boundary. Most agree that it represents people acting in believable and consistent ways and even students without an immigrant background or history of scholastic struggle can recognize familiar elements that lend fidelity to Rose's depiction of the difficulties of being raised with socio-economic challenges and educated in oppressive schools. Richard Rodriguez' (1982) Hunger of Memory does not score as highly with some students when these standards are applied. Most agree that his presentation is coherent, but some are critical of his portrait of the son's rejecting parents and family in order to go forward. Students whose parents are immigrants have been particularly outspoken in articulating their view that Rodriguez' story makes no sense in their view of the world.

Although Fisher's standards for judging a good narrative remain contested (bound as they are to culturally determined values), they are useful in modeling a framework for assessing storytelling that moves away from judging texts to be right or wrong to offer more relative standards based on what we believe to be humane and truthful. Our sense of fidelity is based not on idiosyncratic identification with a character but on the character's appeal to broadly held, long-standing communal values, such as "truth, the good, beauty, health, wisdom, courage, temperance, justice, harmony, order, communion, friendship and oneness with the Cosmos" (as cited in Griffin, 2006, p. 346). These ethical values help us to judge good narratives, which in turn, he argues, provide us with thoughts and actions to model. 
To enrich evaluative criteria, students can add the standards of "appropriateness" and "timeliness" that Candace Spigelman (2004) defines by drawing on Aristotelian rhetoric in the first chapter of Personally Speaking. Explaining "appropriateness," she points out that personal disclosure should not "distract from or confuse terms of debate" (p. 20), but spark feelings of empathy and catharsis in the audience, who as a result of "fellow feeling" are moved toward new or expanded understanding. "Timeliness" goes to the degree to which the personal story makes a relevant point at a critical moment. It is of no scholarly value to talk about a personal event unless that event is contested within our culture. Spigelman is very clear about the grounds for using personal voice narrative: it must advance an argument rather than simply indulge a writer's urge to "cathartically confess" (p. 6). She generates this rule to determine whether personal experience is integral to making an appeal that combines "emotions with reason and ethics" (p. 19): "Ultimately, we might say, no topic is of itself more or less appropriate to public discourse; rather it is a question of the purposes to which the topic is put and a question of the purpose that treatment of the topic serves" (italics hers, p. 22).

Reading Spigelman and Fisher allows students to think about narrative as a way to make meaning or serve as a form of evidence. Narratives do not trade in facts, solve problems or attempt to tell "truths"; instead they are satisfying to the degree that they abide by standards of coherence, fidelity, appropriateness and timeliness: they engage with contested issues in human life in believable ways. Two good narratives can take a different view of the same issue. I have already noted how some students prefer the fidelity achieved by Mike Rose in Lives on the Boundary to that attained by Richard Rodriguez in Hunger of Memory. Yet some students support Rodriguez' depiction, and claim that his story is both motivated and life-like. This difference of opinion is not something to be settled, but instead exposes the capacity of narrative to offer and stimulate contrasting viewpoints. Certainly, Rose and Rodriguez offer contrasting views of literacy education. Both tell about growing up in America in poor immigrant families, but each says very different things about the education system. Rose (1990) emphasizes the need for change in the system itself. For example, he is critical of how little vocational educational actually offers:

Vocational education has aimed at increasing the economic opportunities of students who do not do well in our schools. Some serious programs succeedin doing that, and through exceptional teachers-like Mr. Gross in Horace's Compromise-students learn to develop hypotheses and troubleshoot, reason through a problem, and communicate effectively - the true job skills. The vocational track, however, is most often a place for those who are just not making it, a dumping ground for the disaffected. (p. 26)

Rodriguez is perhaps more ambivalent, but tells a story of loosening ties with family and entering a system that changed him, making the point that a change process is a necessary if painful requirement to enable students to learn what is being taught. The following claim by Rodriguez (1982) can be read as an indictment of Rose's liberal position:

Radical educationists meanwhile complain that ghetto schools "oppress" students by trying to mold them, stifling native characteristics. The truer critique would be just the reverse: not that schools change ghetto students too much, but 
that while they might promote the occasional scholarship student, they change most students barely at all. (p. 68)

Because these authors present sensible yet opposing views, students see that narrative is richly exploratory rather than definitive.

\section{Supporting Narrative Across Disciplines: Feminism and Post-Modernism}

The next move is to identify some of the reasons for the current turn to narrative-in particular, how feminism and postmodernism have supported a narrative approach to theorizing. Assigning a second narrative argument that asks students to examine how a particular theory or theorist has influenced contemporary narrative inquiry practices supports this work and affords another opportunity to explore writing this hybrid form. Students are more confident that they understand the demands of the form, yet most find it resistant to formula for the second essay seldom blends narrative and argument in the same way as the first. For example, if in the first narrative argument writers used the recommended journey metaphor to account for the accretion of their knowing, in this assignment, I suggest that after opening with a passage that grounds their perspective, they move to interspersing self-reflective narrative passages with more traditional analytical passages. Writing two narrative arguments is an invitation to learning for themselves that this form cannot be defined by a single pattern.

A good place to begin discussing the link between feminist theory and narrative inquiry is by reviewing feminist standpoint theory. According to this theory, women's marginality positions them to have an alternative perspective that is not shaped by participation in mainstream traditions, enabling transgressive insight and actions. Boundaries are not only exclusionary and limiting, but can also empower vision and movement. By this theory one's location becomes part of the subject-a condition of seeing and knowing - and thus drives personal investment and narrative development. As Jane Tompkins (1999) says in "Me and My Shadow," her narrative theorizing the role of the personal in knowing, "The insight that my ideas are all products of the situation I occupy in the world applies to all of my ideas equally" (p. 385).

More broadly, feminist scholars have cultivated a non-traditional form of personal narrative writing, using a non-authoritarian, exploratory prose style that makes room for references to life and experience rather than privileging textuality and prior scholarship. Often in feminist criticism, objectivity and forming abstractions gives way to cultivating insight by seeing details and moments from a personal vantage point. Theorizing is offered as changeable and provisional, not a way of entering the traditional arena of debate to articulate grand theory. Feminist literary critic Marianna Torgovnick (1999) describes her commitment to writing in a new way, exploring new forms, in an effort to express herself more fully and interest readers rather than simply following the form favoured by a masculinist academy. She offers the following passage discussing Malinowski's contribution to ethnographic method as an example of uninspired, riskfree, tradition-bound academic prose:

Malinowski founded what is called functionalism in anthropology, the theory (and derived method) that explains all elements of a culture in terms of interlocking functions: the ethnographer explicitly "constructs" a model in which all parts are presumed to contribute to a whole that is organic and unified (though quirkier than a machine). To make his construction, the ethnographer lives inside 
the culture, inhabits it as a text. He tries to replicate the native's point of view, which is the ground and touchstone of meaning and "accuracy." Functionalism leads, in anthropology, to what is called structural functionalism and then, later, to structuralism.

A point-by-point analogy with New Criticism and other formal approaches exists. Here too the "student" (critic) inhabits the text, assuming the unity of the parts as a whole and constructing an account of that whole in the interlocking functions of its parts (pp. 398-99).

She offers the following more whimsical and original passage as the version she prefers, for it is lit up by flashes of insight and empathy, so that she proffers what she knows in ways that invite the reader not only to think but to see, sense, and imagine:

Malinowski's body looks like Lord Jim's. . . It's a small body, well fed but not kindly disposed enough toward itself to put on flesh. It has a narrow chestpale, with just a few hairs and no nipples to speak of. It has thin legs yearning for massive thighs; in fact if this man does put on weight in later life (and he may) it will show in his thighs first. The buttocks lie flat, unwelcoming, with maybe a stray pimple. The penis is a center of anxiety for him but is in fact no smaller-and bigger-than anyone else's. It's one of the few points of identification he can settle on between his body and theirs.

Their bodies—almost naked—unnerve him. His body needs its clothes, his head its hat. He rarely looks at his body-except when washing it. But he has to look at theirs. The dislike he sometimes feels for the natives comes over him especially when in the presence of their bodies. ... He looks at their bodies and takes notes about size, ornamentation, haircuts, and other ethnographic data. $\mathrm{He}$ takes photographs. (pp. 396-97)

This narrative example, a clear revision of the first more traditional approach to presenting critical argument and observation, demonstrates what feminist writers have in mind when they refer to developing an alternative discourse. Because Torgovnick writes well in both versions, students are able to see strengths and weaknesses in both approaches and thus can explore without over simplifying the risks and advantages of moving from traditional argument to personal narrative. This continues work started in the last unit aimed at understanding the role of narrative-how it presents evidence and forms an argument-in scholarly contexts.

Another example of a feminist narrative that takes the personal as its focus and theorizes this approach is "Modern Love" in Janet Carey Eldred's (2005) volume of personal essays, Sentimental Attachments. She describes her relation to her mother and dissects the accomplishments and implications of her mother's life, mindfully reflective of the responsibility she as writer is assuming/presuming by talking about someone else-in this case a deceased loved one no longer able to approve, protest or correct Eldred's version. Theorizing her work, Eldred speaks directly about the cultural urgency, post $9 / 11$, of finding a way to talk about strong emotions, so that we abandon the tone of irony and cynicism made popular by modernist essayists for warmer engagement and commitment to exploring sentiment and connection: "We are essaying with all our new technologies, in a new millennium, but we can expect the same old, unsure voice to repeatedly greet us, unless we're willing to detach occasionally from detachment and irony-to engage loss and employ depth and gendered range of 
sentiment" (p. 67). Here the writer's standpoint not only influences but is the subject in an embodied form of writing that accommodates personal voice, stories, vision, and emotion. Because this essay is recent and written by a compositionist, it presents students with an updated example and analysis of the role of the personal in feminist writing.

Perhaps the best place to begin examining the link between narrative and the broad category of post modernity is to point out that the so-called "turn" to both which occurred around the mid-twentieth century has continued to gain widespread academic and popular currency as time has progressed. A narrative text accommodates many postmodern values. For example, the deconstructivist interest in the role of interpretation and subjectivity in knowing is served by research in the form of storied accounts, understood as filtered through the writer's perspective. Narratives also respond to discourse theories that foreground the symbolic nature of language and the participatory role of the reader in meaning making. In offering a narrative account, the writer not only offers a particular perspective but one mediated by language choices, which in turn will be subject to further such mediation when taken up by the reader, who is recognized as contributing to the process of meaning making. Finally, a critical perspective linking power and discourse is comfortably housed in a narrative text, for this framework suggests that the text is a construction, drawing upon other narratives and offered as a true-for-now version. Stuart Hall (as cited in Griffin, 2006), for example, recommends abandoning a social science research approach to understanding human communication for a form of writing ripe with narrative elements-to abandon "translating matters that have to do with signification, meaning, and symbolization into crude behavioral indicators"( p. 370). When students elect to write their second narrative argument linking the narrative turn to post-modern thinking, I recommend that they focus on and respond to one of these theorists, going deep rather than taking a broad cook's tour of post-modern thought.

\section{Narrative: Ethos and Pathos}

A relatively recent memoir-cum-fiction like Dave Eggers's (2000) Heartbreaking Work of Staggering Genius provides a good example of postmodern narrative, particularly because it opens with a preface and introduction that question modernist/traditional narrative conventions and offer alternative post modernist strategies. Although its fictional element would seem to remove it from the category of most interest here-scholarly narratives, or narrative texts that teach-the introductory sections theorize in personal voice what he and other writers can do in times when it is assumed they cannot tell truths. He tells us that the story resists genre definition, that the readers can decide what it means, that the author knows he cannot tell biographical truths, and that the author has assembled fragments and created pastiche rather than a consistent narrative line. These opening pages are one of several places in the text where he breaks from the frame of the story to speak directly to the reader, telling us about his choices as writer and collaborating with us about our choices as readers, in a move that recognizes meaning lies not within the words themselves but is interpretive and constructed. Moreover, the narrative he provides us, conventional at first but increasingly fragmented and self-centered as it goes forward, conveys some of the 
essence of contemporary life, in being narcissistic and uneven, like a slice of reality television come to text.

Eggers's text provides a springboard into dealing with a topic students of narrative need to grapple with at this stage: that is, the relation of narrative to truth telling. If everything is contextualized and shifting and created by language, then socalled non-fictions are really more created/creative than actual or authentic. The editor of Creative Nonfiction, Sarah Redfield (2000), has forcefully discouraged this interpretation by arguing that "Creative doesn't mean making up. It must be understood that there's no room for invention in this genre" (p. 37). Yet after having seen so much theory and evidence weighted in favour of the position that language and narrative cannot represent actual experience with any authenticity - that text worlds are necessarily perspectival, interpretive, and provisional-students tend to be awash in their own crises of representation, and need to reflect on the stability and fluidity of meanings. Comparing Eggers's Heartbreaking Work of Staggering Genius to James Frey's (2004) A Million Little Pieces shows students the work of two writers who push at generic boundaries separating fictional and non-fictional worlds, but who pursue different strategies for doing this, particularly in the relationship each strikes with readers. Eggers talks to us about his experiment with breaking boundaries, while Frey simply moves into the realm of invention under the banner of life writing. While some students defend Frey's choice-pointing out that it is naïve to expect any writer to be capable of performing a reenactment of life in story - the point of comparison is that the two writers make different generic and even ethical decisions about dealing with matters of narrative accuracy.

A book review assignment inviting personal voice reader response allows students to consider further what, if anything, writers owe readers-if texts cannot tell truths, can we still expect authors to be concerned about matters of ethos and authenticity? If authors know that they cannot recreate events with accuracy, should they still call textual evocations, pale shadows of events, "memoirs"? Should they use the term "memoir" if they have made no effort to recreate actual events or, as in the case of Frey, if they have made up events, in a fashion we are used to calling fiction? Should the term "memoir" be stretched to accommodate the way language mediates reality? Asking students to write a reflective review to compare these books provides a way for them to focus their thinking on open-ended questions about narrative authenticity. They can learn first hand the way that taking a narrative approach can help to resolve some of the tensions arising for a writer who attempts to respond to questions that resist definitive analysis. Yet the exercise of comparing Eggers to Frye has further uses. Comparing the work of a writer who presents text as a self-conscious and admitted mix of fact and fiction with that of a writer who offers fiction as fact helps students to think through the complexities that inform the relation of narrative text to life world. Doing this work also prompts them to consider how the element of play has entered the textual acts of reading and writing, particularly with contemporary notions of structural impermanence/permeability fostered by our hours of internet reading. What duties and pleasures are open to readers whose understanding is filtered through cultural discourse and who thus participate in meaning making?

Finally, by looking at Simon Wiesenthal's (2002) The Sunflower, students confront the power of narrative to move audiences and to unsettle and layer human 
questions. At the end of his tale about Holocaust torture and survival, Wiesenthal asks readers if he was right to withhold forgiveness from a dying Nazi soldier, one who Wiesenthal describes having perpetrated hideous crimes. Following Wiesenthal's story is a collection of about 50 responses from various accomplished contemporary religious leaders, writers and philosophers, all thoughtful and wise. Students usually read the narrative first and formulate an answer to Wiesenthal's question based on their experiences and views. Most revise or expand these views by reading the symposium responses, as well as by listening to their peers. Our discussion of this powerful text is in no way exhaustive, but aimed at showcasing the power of narrative to provoke thinking and feeling, able to incite a variety of narrative responses amongst readers. Perhaps a more important demonstration is the way in which narrative reveals itself to be a flexible framework, since the story each participant tells of their response to the text is in turn responsive to change and revision. No one view is definitive, and the most convincing and interesting views result from intersubjectivities.

\section{Reading and Writing Narrative}

In a class devoted to studying narrative and knowing, there is enough time to examine both theory and examples. In the actual class, I tend to introduce more narrative examples and spend more class time discussing them than I may have indicated in this essay, for my intention here has been to foreground the theoretical components often underrepresented in many classrooms to make the case that narrative theory is a necessary ballast to the practice of narrative writing. In the class itself, I frequently ask students to read examples first, before introducing relevant theorizing texts. It makes sense for a course in narrative inquiry to unfold according to narrative principles-letting ideas form and build, allowing students to make connections that resonate with them, rather than working deductively to demonstrate theoretical ideas.

Moving from examples to theory is an approach that can be risky for some students. Some enjoy the relative simplicity of story and resent what they see as the imposition of needlessly abstract thinking. If they grow frustrated by the time-consuming but productive process of learning from back and forth movement between example and theory, they almost certainly resist attempting the further challenge of learning from a richly trialectical movement amongst textual example, theory, and personal experience. However, there are rich rewards for those willing to do the work of making connections.

\section{References}

Bissex, G.L. (1996). Small is beautiful: Case study as appropriate methodology for teacher research. Partial truths: A memoir and essays on reading, writing, and researching. Portsmouth $\mathrm{NH}$ : Heinemann.

Bruner, J. (1986). Two modes of thought. Actual minds, possible worlds. Harvard UP.

Bruner, J. (2002). So why narrative? Making stories: Law, literature, life (pp. 89-107). New York: Farrar, Strauss and Giroux.

Clandidin, D. J. \& Connelly, F.M. (1990, June-July). Stories of experience and narrative 
inquiry. Educational researcher. 19 (5), 2-14.

Clandidin, D. J., \& Connelly, F. M. (2000). Why narrative? Narrative inquiry: Experience and story in qualitative research (pp. 1-20). San Francisco: Jossey Bass.

Coles, R. (1989). The call of stories: Teaching and the moral imagination. Boston: Houghton Mifflin.

Donald, J. (1999). Imagining the modern city. Minneapolis: University of Minnesota Press.

Eggers, D. (2000). A heartbreaking work of staggering genius. New York: Simon and Schuster.

Eldred, J. C. (2005). Sentimental attachments: Essays, creative nonfiction, and other experiments in composition. Portsmouth $\mathrm{NH}$ : Heinemann.

Frey, J. (2004). A million little pieces. New York: Anchor.

Griffin, E. (2006). A first look at communication theory (6 $6^{\text {th }}$ ed.). Boston: McGraw.

Lewiecki-Wilson, C. (1999). Reflecting on the (re-?)turn to story: Personal narratives and pedagogy. College composition and_communication. 51, 96-109.

Lunsford, A. A. (1999). "Creative non-fiction": What's in a name? In R.L. Root, Jr. \& M. Steinberg (Eds.), The fourth genre: Contemporary writers of/on creative nonfiction (pp. 345-57). Boston: Allyn and Bacon.

Ong, W. (2002). Orality and literacy: The technologizing of the word. London: Routledge.

Polanyi, M. (1958). Personal knowledge: Towards a post-critical philosophy. New York: Harper and Row.

Redfield, S. H. (1999). Surveying the boundaries: An inquiry into creative nonfiction. Poets and writers, 27 (5), 36-41.

Rodriguez, R. (1982). The achievement of desire. Hunger of memory: The education of Richard Rodriguez. Boston: Goodine.

Rose, M. (1990). I just wanna be average. Lives on the boundary. New York: Penguin.

Spigelman, C. (2004). Personally speaking: Experience as evidence in academic discourse. Carbondale: Southern Illinois UP, Studies in Writing and Rhetoric Series. 
Soja, E. W. (1996). Thirdspace: Journeys to Los Angeles and other real-and-imagined places. Cambridge, Mass.: Blackwell.

Tompkins, J. (1999). Me and my shadow." In R. L. Root, Jr. \& M. Steinberg (Eds.), The fourth genre: Contemporary writers of/on creative non-fiction (pp. 38295). Boston: Allyn and Bacon.

Torgovnick M. (1999). Experimental critical writing. In R. L. Root, Jr. \& M. Steinberg (Eds.), The fourth genre: Contemporary writers of/on creative non-fiction (pp. 396-400). Boston: Allyn and Bacon.

Wiesenthal, S. (2002). The sunflower. New York: Schocken.

Wood, J. T. (2004). Narrative theory. In Communication theories in action (pp. 104-115). Toronto: Thomson.

\section{Bio}

Jaqueline McLeod Rogers is an Associate Professor in the Department of Rhetoric, Writing and Communication at The University of Winnipeg. She has recently coauthored a rhetoric textbook (Across the Disciplines: Reading and Writing, published by Pearson) and published articles on student narrative (Rhetoric, Uncertainty, and the University as Text: How Students Construct the Academic Experience), on student ethnographies (in Undergraduate Research in English Studies-NCTE), on Margaret Mead's ethnographic work (Ethnologies) and on city rhetorics (Writing on the Edge).She recently co-convened a conference focusing on the work of Marshall McLuhan and presented a paper applying McLuhan's theories to explain how teen girls and their mothers use the internet.

\footnotetext{
${ }^{1}$ I am referring to anthologized discussions of Walter Fischer's theory that appear in texts intended to teach modern rhetorical theory (in both Wood and in Griffin) because students can easily grasp Fischer's ideas in this form and for the purposes of class discussion students need a working understanding of his position, rather than thorough-going immersion. Students can be challenged with the option of consulting original sources as part of a narrative essay writing assignment.
} 